\title{
CORRECTION
}

\section{Correction to: Investigation of Damping Characteristics on Copper-Based Shape Memory Alloy Frictional Damper in Boring Process}

\author{
Chockalingam Singaravelu ${ }^{1} \cdot$ Prasannavenkadesan Varatharajan $^{2} \cdot$ Ganesan Ramu ${ }^{3} \cdot$ Karthikeyan Alagappan $^{4}$
}

Published online: 23 June 2021

(c) King Fahd University of Petroleum \& Minerals 2021

\section{Correction to: \\ Arabian Journal for Science and Engineering https://doi.org/10.1007/s13369-021-05719-z}

In the original publication, the cross reference of the corresponding author affiliation was wrong. It should be "Chockalingam Singaravel ${ }^{1 "}$. The original article has been corrected.

The original article can be found online at https://doi.org/10.1007/ s13369-021-05719-z.

Chockalingam Singaravelu

smslogu@gmail.com

1 Department of Mechanical Engineering, E.G.S. Pillay Engineering College, Nagapattinam, Tamil Nadu 611002, India

2 Department of Mechanical Engineering, Indian Institute of Information Technology Design and Manufacturing, Kancheepuram, Chennai, Tamil Nadu 600127, India

3 Department of Mechanical Engineering, Dr. Kalam Polytechnic College, Thanjavur, Tamil Nadu 614623, India

4 Department of Mechanical Engineering, Thamirabharani Engineering College, Tirunelveli, Tamil Nadu 627358, India 